\title{
Custos no serviço público
}

Revista do

Serviço

Público

Ano 50

Número 1

Jan-Mar 1999

Marcos Alonso ${ }^{1}$

\section{Custos e qualidade do gasto público}

Imagine que o cenário econômico do Brasil atual fosse o do início dos anos 70, quando a economia nacional apresentava altas taxas de crescimento econômico, pleno emprego, inflação tolerável, contas públicas saudáveis (superavit fiscal estrutural e baixo nível de dívida pública) e equilíbrio nas contas externas. Nesse período, conhecido como milagre econômico, não havia crise do Estado nem crise da economia. Era compreensível, naquele contexto, que não houvesse grande incentivo para discutir o tema custos no serviço público. A partir dos anos 80, com a intensificação da crise fiscal do Estado e a maior exposição da economia nacional à competição internacional, o Estado foi forçado a reorientar a política econômica e, em particular, conter suas despesas. Dada a dificuldade política de aumentar a carga tributária, especialmente a tributação direta, a palavra de ordem passou a ser cortar gastos. A política de corte de gastos atravessou a década de 80 e entrou na década atual alcançando o limite de suas possibilidades. Esta percepção não se restringiu aos economistas acadêmicos, mas passou a integrar o discurso do Banco Mundial e do próprio Fundo Monetário Internacional (FMI). ${ }^{2}$ Estes organismos internacionais vêm enfatizando a qualidade do gasto público, e não simplesmente o corte do gasto público. Ambos têm se empenhado em introduzir o tema "qualidade do gasto público" na agenda de reforma do Estado de diversos países, entre eles o Brasil.

Como as informações sobre os gastos do governo em geral são organizadas com vistas às necessidades da administração financeira (fluxo de caixa do Tesouro Nacional), o governo sempre teve noção de quanto

Mestre em Economia pela USP. Especialista em Políticas Públicas e Gestão Governamental, atualmente na Assessoria da Secretaria de Estado da Administração e do Patrimônio/ SEAP / MOG 
precisaria cortar em decorrência do equilíbrio macroeconômico, mas nunca soube ao certo como e onde deveria cortar. Ou seja, o governo nunca teve condições de promover cortes seletivos de gastos, de modo a não comprometer ainda mais o desempenho da administração pública. Assim, a redução de gastos com melhoria de desempenho tornou-se uma alternativa impraticável, ainda que necessária. Ao comprometer a qualidade dos serviços públicos, os cortes de despesa comprometem, por extensão, a competitividade da economia nacional, dado o caráter sistêmico da competitividade.

A importância do tema "custos no serviço público" pode ser avaliada pelo crescente número de iniciativas governamentais em vários países na última década e pelo espaço que vem ganhando na literatura especializada. Sem dúvida, a iniciativa mais abrangente e avançada é a da administração pública federal americana (Governo Clinton). ${ }^{3}$

No Brasil, o controle dos gastos públicos experimentou um formidável avanço a partir de 1986, com a criação da Secretaria do Tesouro Nacional, do Ministério da Fazenda. O desenvolvimento e a implantação do Sistema Integrado de Administração Financeira (SIAFI) significaram uma verdadeira revolução na gestão das finanças públicas no Brasil. O avanço foi tão significativo que, já no início desta década, o Brasil passou a ser referência internacional no controle informatizado de gastos governamentais. Não obstante os avanços, o Siafi, como se sabe, tinha por objetivo controlar a execução da despesa. Este sistema não foi concebido para apurar custos dos serviços públicos, motivo pelo qual sua estrutura de dados não informa os produtos e processos de trabalho dos órgãos do governo. Daí a oportunidade de se propor sistemas de custos na presente reforma.

A diferença conceitual entre despesa e custo tem particular interesse no contexto atual. Enquanto a despesa é o desembolso financeiro correspondente a atos de gestão do governo, o custo mede o consumo de recursos na produção de um bem ou serviço (custo do produto). $\mathrm{O}$ custo também mede o consumo de recursos pelas atividades das organizações governamentais (custo da atividade ou de processo). Como ilustração da distinção entre despesa e custo, basta observarmos que, quando a administração pública compra material de consumo (recurso), são feitos dois lançamentos contábeis de mesmo valor nas contas: 1) despesa com material de consumo (despesa) e 2) estoque de material de consumo (ativo). A despesa só é contabilizada como custo no momento em que alguma unidade faz a requisição do material de consumo junto ao almoxarifado. A contabilização da despesa como custo requer a apropriação desta a algum produto (no custeio tradicional) ou a alguma atividade (no custeio baseado em atividade). Detalhes sobre as definições conceituais e a 
classificação dos custos podem ser obtidos no Anexo I deste texto. Por ora, basta lembrar que as despesas nos mostram como o governo financia os recursos que usa ou potencialmente poderá utilizar — despesa com pessoal, com material de consumo, com equipamento e material permanente, com serviços de terceiros, despesas financeiras etc. - enquanto os custos nos mostram como o governo financia seus resultados - custo de uma aula, de uma consulta médica, de um serviço administrativo, custo de uma operação de fiscalização etc. Na contabilidade pública, as despesas se confundem com gastos do governo. Na contabilidade privada (lei das S.A.), o gênero gastos contempla as espécies despesa e custos (maiores detalhes no Anexo I).

Com os sistemas de informação existentes, incluído o Siafi, o governo não sabe em que medida cada tipo de despesa contribui para os resultados obtidos. Mais ainda, ele não sabe quais atividades agregam valor ao resultado final das ações de governo. Também ignora qual é a taxa de consumo de recursos pelas atividades e quanto custam os processos de trabalho ou os programas governamentais. O governo desconhece, em resumo, onde há desperdício e onde há eficiência na aplicação dos recursos. De fato, o modelo de gestão tradicional do setor público prioriza o controle dos recursos e dos procedimentos formais, e não os resultados, o desempenho, a eficiência.

O conhecimento do custo dos serviços públicos é fundamental para se atingir uma alocação eficiente de recursos. $\mathrm{O}$ desconhecimento dos custos é o maior indicador de ineficiência no provimento dos serviços públicos.

Um exemplo clássico de atividade que consome volumes substanciais de recursos e que não agrega valor aos usuários de serviços públicos é a atividade de controle (administrativo, interno ou externo). Tecnicamente tais atividades não agregam valor, pois, caso fossem suspensas, não impediriam a prestação de serviços ou alterariam a satisfação do cliente ou usuário do serviço. Assim, ainda que tais atividades devam ser executadas por imposição legal, elas podem e devem ser racionalizadas, até porque não agregam valor ao usuário dos serviços públicos.

Pelo exposto acima, não há dúvidas de que o tema "custos no serviço público" é extremamente oportuno e terá importância crescente para a administração pública.

\section{Custos e governo de resultados}

O esgotamento do modelo de gestão (tradicional ou burocrático) da administração pública, no Brasil e no exterior, é um diagnóstico bem estabelecido na literatura especializada e na experiência internacional de reforma do Estado. Enquanto o modelo tradicional enfatiza os controles 
formais e o estrito cumprimento da lei, os modelos de gestão que vêm sendo propostos e desenvolvidos em programas de reforma da administração pública enfatizam a melhoria no desempenho ou simplesmente resultados. É o que Osborne denominou governo de resultados.

Para que os recursos e as energias da administração pública estejam orientados para resultados, é necessário que o perfil dos gerentes e os sistemas de informações estejam totalmente alinhados com essa orientação. Se os modelos de gestão não dispuserem de sistemas de informação que avaliem o desempenho presente e apontem as tendências do desempenho futuro, então dificilmente a reforma será bem-sucedida. Para avaliar adequadamente o desempenho do serviço público, é crucial que os sistemas de informação do governo disponham de uma informação gerencial mais refinada que a despesa: os custos.

\subsection{Custos e competição administrada}

Ao longo dos últimos anos, vem sendo muito destacada a perspectiva de se introduzirem mecanismos competitivos na administração pública, de modo a melhorar seu desempenho. Trata-se do conceito de competição administrada ou do que Osborne chamou de governo competitivo. ${ }^{4}$ Entretanto, a introdução de mecanismos competitivos não significa que a estratégia competitiva irá impregnar todas as atividades governamentais. Sem dúvida, uma estratégia cooperativa poderá ser bem mais eficaz em muitas ações de governo. O sucesso de novos modelos de gestão da administração pública será determinado exatamente pela integração adequada das estratégias competitiva e cooperativa.

Como se sabe, para a maioria das atividades do serviço público não prevalece a lógica de mercado. Por essa lógica, o mecanismo de preços orienta os agentes econômicos nas suas decisões de comprar ou vender bens privados. Quando o preço sobe, é porque há excesso de demanda do produto. Em caso de excesso de oferta, o preço cai. No caso dos bens públicos, não há como regular "via preços" a produção e o consumo. É possível conceituar a oferta, mas não a demanda. De fato, os usuários atribuem importância (utilidade) aos serviços públicos, mas, na acepção de Samuelson, "não revelam sua preferência". Esse é o caso dos programas governamentais que promovem melhoria da qualidade ambiental. Claramente os cidadãos de uma cidade poluída estarão dispostos a pagar pela melhoria da qualidade do ar. Entretanto, os que não pagarem não terão como ser excluídos do consumo do ar mais limpo. Ou seja, o consumo de bens públicos é não-excludente. Além disso, o consumo de mais ar limpo por um cidadão não reduz o consumo de ar limpo dos demais. Sendo assim, o consumo de bens públicos é não-rival. Em resumo, os bens ou serviços públicos apresentam consumo não-excludente e não-rival, razão pela qual 
fica difícil estimar o preço que o usuário estaria disposto a pagar pelo serviço público. Em outras palavras, não é possível determinar a curva de demanda desses bens. ${ }^{6}$ São exemplos de bens públicos: os serviços de segurança nacional prestados pelas Forças Armadas, os serviços de segurança pública, serviços judiciários, entre outros.

A oferta dos bens públicos, por outro lado, é bem definida, pois, em princípio, é possível estimar o custo dos serviços públicos. Trata-se, portanto, de um mercado sem o lado da demanda. Conseqüentemente, não há sinalização de preços ao mercado. Isso não significa, entretanto, que não seja possível instituir mecanismos competitivos no provimento dos serviços públicos. Acompetição "via preços” poderia ser substituída pela comparação de desempenho "via indicadores de desempenho". A comparação de desempenho poderia envolver unidades prestadoras de serviços similares, equipes de trabalho que desempenham funções semelhantes, processos de trabalho similares etc. A competição administrada alcança também os programas de terceirização e de concessão/permissão de serviços de utilidade pública. Assim, ainda que não se possa aplicar a regra de mercado, é possível maximizar resultados no setor público. Nesse caso, os indicadores de desempenho, entre eles os indicadores de custos, fariam o papel de "variável proxy" dos preços de mercado.

Os indicadores de custos também são cruciais na implementação de estratégias cooperativas. $\mathrm{O}$ sucesso de parcerias da administração pública com instituições comunitárias, privadas ou com outras esferas de governo depende, e muito, de medidas de desempenho. Não faz sentido estabelecer parcerias em que o custo das atividades é maior que o custo praticado pela administração pública ou por instituições não-governamentais, até porque as parcerias quase sempre utilizam recursos públicos, e estes estão sujeitos ao (novo) princípio (constitucional) da eficiência. Ou seja, a concepção moderna de parceria pressupõe uma adequada gestão de custos.

\section{Evolução histórica dos sistemas de custos}

Ao contrário do setor privado, as experiências com sistemas de custos no serviço público são bem recentes. Salvo algumas experiências isoladas, ${ }^{7}$ pode-se dizer que não há cultura de custos no serviço público no Brasil. Isso também vale para a maioria das economias desenvolvidas, especialmente no tradicional setor público. Já nas empresas estatais, pela sua relação direta com o mercado, ainda que em regime monopolista, sempre houve a necessidade de se produzir alguma informação sobre custos, pois o mercado requeria uma regra de formação de preços (dos produtos produzidos pelas estatais). A legislação ${ }^{8}$ impunha a obrigatoriedade de avaliar estoques e de apurar lucros, donde foi reforçada a necessidade de 
sistema de custos. Porém, pelo seu caráter monopolista, as empresas estatais nunca tiveram, regra geral, incentivo para apurar custos com maior

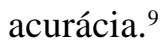

No setor privado, os sistemas de custos tomaram impulso no início do século, no bojo do movimento de administração científica. Naquela época, os custos eram apurados basicamente nas indústrias, e os custos de produção compunham grande parte do custo total das empresas. $\mathrm{O}$ custo da mão-de-obra, em particular, tinha grande importância na composição dos custos diretos, sendo um referencial para o rateio dos indiretos. O método de custeio por absorção ${ }^{10}$ tornou-se generalizado nas empresas industriais ao longo deste século. A própria legislação das sociedades anônimas, no exterior e no Brasil, estabeleceu a obrigatoriedade da adoção de sistemas de custos para empresas de médio e grande porte. As empresas também demandavam sistemas de custos para a precificação de produtos. Não havia, ou não era prioritária na fase de consolidação desses sistemas, a preocupação de se utilizarem medidas de desempenho dos processos de trabalho ou da organização como um todo. A preocupação das empresas ao apurá-los foi, via de regra, a geração de relatórios financeiros.

A partir dos anos 70, o progresso tecnológico e a integração da economia mundial produziram importantes mudanças nas estruturas produtivas, nas técnicas de administração de empresas e na contabilidade de custos. Ressaltamos as seguintes mudanças:

— aumento da mobilidade de fatores de produção em decorrência da redução dos custos de transportes e de comunicações, promovendo novas reduções de custos e aumento da competição;

- aumento relativo da importância do setor de serviços em relação à indústria (em termos de proporção do Produto Interno Bruto);

- prevalência dos custos indiretos em relação aos diretos, na maioria dos processos produtivos (na indústria e nos serviços);

- prevalência dos custos fixos em relação aos variáveis, na maioria dos processos produtivos (na indústria e nos serviços);

— introdução da competição internacional em mercados anteriormente não-concorrenciais ou protegidos pela economia fechada, aumentando o papel estratégico dos custos;

— maior instabilidade nos padrões de mercado (efeitos da propaganda sobre as preferências dos consumidores, surgimento de novos produtos, redução no ciclo de vida dos produtos, incertezas quanto a custos financeiros, de commodities e de matérias-primas), produzindo alterações profundas e recorrentes nas estruturas de custos das empresas.

Nas três últimas décadas, os custos passaram a ser fator ainda mais decisivo na competitividade internacional. Nesse período, a metodologia de custeio tradicional mostrou suas limitações, produzindo 
profundas distorções na apuração do custo dos produtos e dos processos de trabalho. A busca de novas metodologias de custeio passou a ser crucial para empresas inseridas em mercados competitivos, especialmente onde os processos produtivos eram complexos e mutantes. Foi aí que surgiu, na segunda metade dos anos 80, o Custeio Baseado em Atividade $(\mathrm{ABC})$. O ABC surgiu originalmente na indústria, mas mostrou-se igualmente bem-sucedido no setor de serviços (privados). Recentemente, a partir do governo Clinton, o ABC teve seu uso generalizado pela administração pública, dentro e fora dos EUA. ${ }^{11}$

Foge ao escopo do presente texto uma análise comparativa da evolução dos métodos de custeio. Basta para o objetivo deste trabalho registrar que, ao longo do século, os sistemas de custeio evoluíram muito, que o $\mathrm{ABC}$ é uma metodologia reconhecidamente mais eficaz que suas antecessoras e que veio para ficar, não se tratando de um "modismo". De fato, o ABC superou parte substancial das limitações das metodologias tradicionais, ainda que com implementação mais elaborada e onerosa. ${ }^{12}$

\subsection{Por que apurar o custo dos serviços públicos?}

Como já foi observado acima, a crise fiscal do Estado e a exposição dos mercados domésticos à competição internacional impuseram a necessidade de que a reforma do Estado privilegiasse a qualidade do gasto público. Diferentemente do setor privado, no setor público as preocupações com a gestão de custos não estão relacionadas com a avaliação de estoques ou com a apuração de lucros, mas sim com o desempenho dos serviços públicos. A melhoria substancial no desempenho de uma organização governamental, por sua vez, requer sistemas de informações gerenciais que dêem sustentação aos seus processos decisórios. Em particular, tais sistemas devem contemplar medidas de resultados e o custo para obtê-los.

A medição de resultados ainda é feita de forma não sistemática e/ ou inadequada na administração pública federal. Porém, com relação à medição de custos, a situação é ainda mais precária, pois não há tradição em se medir custos no serviço público. Perguntas básicas ainda ficam sem resposta:

Quanto custa uma aula?

Quanto custa um determinado serviço de saúde?

Quanto custa a gestão de pessoal?

Quanto custa a gestão de compras?

Quanto custam as auditorias governamentais?

Quanto custam os serviços jurídicos?

Quanto custa a gestão de políticas públicas?

Quanto custam os processos de trabalho no governo? 
Quanto custa atender cada cliente de uma organização governamental? namentais?

Quais atividades agregam valor aos processos de trabalho gover-

Qual é o impacto em termos de custos nas mudanças organizacionais propostas ou implementadas?

Qual é a eficiência de cada organização do governo?

O governo e a sociedade não sabem, regra geral, quanto custam os serviços públicos. Como não há medida de custos, também não há medida de eficiência na administração pública, dado que a eficiência é a relação entre os resultados e o custo para obtê-los. Sem um sistema de avaliação de resultados e de custos, a administração pública abre margem para encobrir ineficiência. Como já foi ressaltado, a inexistência de medidas de desempenho é, por si só, uma forte indicação de ineficiência nas organizações do governo. Sem dúvida é possível promover ações que melhorem o desempenho das organizações do governo sem indicadores de custos, valendo-se, para tanto, do feeling dos gerentes e das equipes. Entretanto, a utilização sistemática de indicadores tem a vantagem de propiciar uma avaliação mais criteriosa e consistente, além de institucionalizar nas práticas organizacionais o compromisso com resultados e o valor pelo dinheiro.

A experiência nacional e internacional tem demonstrado que a apuração e a divulgação de medidas de desempenho constituem um poderoso instrumento nos processos de mudança organizacional, até porque a intensidade da mudança depende da sua percepção. Assim, a apuração e a divulgação dos indicadores de resultado e de custos servem de guia para a mudança organizacional e, ao mesmo tempo, de poderoso incentivo para os agentes de mudança, pois materializam a percepção da mudança. As medidas de desempenho prestam-se, entre outros, para os seguintes objetivos:

- promover a redução de custos com melhoria da qualidade dos serviços prestados;

— instrumentalizar o combate ao desperdício e identificar atividades que não agregam valor ao usuário dos serviços públicos;

- servir de guia para avaliar o impacto efetivo das decisões tomadas;

— tornar clara para toda a organização (e seus clientes) a percepção de melhoria no desempenho, que é um importante fator de motivação;

- promover a mudança da cultura organizacional, introduzindo a dimensão de accountability e de value of money;

- subsidiar o processo orçamentário (no conceito original de orçamento-programa);

- subsidiar a avaliação de planos de reestruturação e melhoria de gestão; 
— servir de parâmetro para a competição administrada entre unidades prestadoras de serviços similares.

A experiência internacional e a literatura especializada ${ }^{13}$ são claras: não é possível se falar seriamente em qualidade sem se falar em custos. A adoção de sistemas de custos é, portanto, condição necessária para a implantação de programas de qualidade. Há melhoria na qualidade dos serviços prestados quando a administração pública consegue prover os mesmos serviços, em quantidade e qualidade, ${ }^{14}$ a custos menores.

Os custos estão entre os principais indicadores de desempenho das organizações. Assim, os sistemas de custos desempenham um papelchave nos processos decisórios e na avaliação do desempenho institucional. No setor privado, os sistemas de custos orientam as empresas sobre a quantidade ideal a ser produzida e sobre o corte dos produtos não-rentáveis. No setor público, o critério relevante não é o da rentabilidade. Mas a identificação de custos elevados em relação a padrões de análise (custo histórico, custo de organizações ou serviços congêneres etc.) poderá orientar a administração pública sobre a necessidade de ações de melhoria de processos ou mesmo a sua reestruturação, terceirização, outorga de concessão, adoção de parcerias, ações de descentralização, adoção de contratos de gestão etc.

A correta apuração dos custos dos serviços públicos e sua publicidade são poderosos instrumentos de controle social, permitindo aos usuários, aos auditores (internos e externos) a avaliação da eficiência dos serviços prestados. De fato, um dos fatores impeditivos para que os sistemas de controle interno e externo possam avaliar a eficiência dos serviços públicos é justamente a inexistência de sistemas de custos. Dessa forma, o controle acaba ficando circunscrito aos aspectos formais e legais dos atos de gestão.

\section{2. É possível apurar custos no serviço público?}

Sim, é perfeitamente possível apurar custos no serviço público, ainda que muitos dos produtos da administração pública sejam ofertados em regime de monopólio, que não sejam bens tangíveis, homogêneos, com preços de mercado não definidos e processos de produção estáveis. Além da histórica falta de motivação para a apuração de custos no serviço público, há também a inadequação dos métodos de custeio tradicionais às características do serviço público. Tal inadequação é um problema tão sério que uma estratégia de modernização do serviço público, com base no custeio tradicional, certamente traria benefícios de alcance limitado e novos problemas para o mesmo. Como no custeio tradicional o custo é 
determinado pelos centros de custos e critérios de rateio, a administração pública poderia ter problemas com a escolha inadequada desses dois elementos, comprometendo os esforços de avaliação institucional que venham a ser empreendidos. De fato, as freqüentes mudanças de estrutura dos órgãos e entidades governamentais determinam uma redefinição dos centros de custos, instabilizando a apuração dos mesmos pelo método do custeio por absorção. Por outro lado, o peso dos custos fixos e indiretos é elevado no setor público, tornando ainda mais problemática a escolha dos critérios de rateio. Daí sustentarmos a tese de que a administração pública deve ser dotada de sistemas de custos $\mathrm{ABC}$, e não de sistemas de custos tradicionais.

Se são necessários e tecnicamente viáveis, então por que os custos nunca foram apurados no serviço público?

As razões são em parte culturais e em parte econômicas. Realmente, à primeira vista, parece desnecessário apurá-los quando o fundamental, no serviço público, é o cumprimento da lei. Cumprindo a lei, o serviço público é eficaz, e ponto final. "Eficiência é um conceito privado", portanto, estranho ao setor público. Esse vem sendo o paradigma do setor público. Não faz parte de sua cultura a consciência de que não basta cumprir a lei, mas que é necessário cumpri-la com bom desempenho, com economia de recursos e com a satisfação dos usuários desses serviços. A eficiência só adquiriu status de princípio constitucional recentemente. ${ }^{15}$

Como as atividades estatais sempre foram executadas em regime de monopólio, consolidou-se, historicamente, a percepção de que o financiamento indireto por meio de impostos cobriria qualquer custo dos serviços públicos, daí a desnecessidade de apurá-los. E, como o nome já sugere, os impostos financiam atividades (monopolistas) do Estado, sem que este precise fazer um esforço especial para justificar seus custos.

Por último, e não menos importante, os agentes políticos do Estado e parte da própria tecnocracia da administração pública resistem à apuração de custos, pois, a partir deles, terão de justificar seu (baixo) desempenho. Valem as máximas:

"Todos são logicamente a favor da avaliação, mas, em sã consciência, ninguém gosta de ser avaliado."

"Avaliação é uma coisa muito boa ... para os outros!!"

\subsection{A apuração de custos trará cortes orçamentários?}

A apuração de custos contribuirá, sem dúvida, para a identificação das atividades que adicionam ou não valor ao usuário do serviço e para combater eficazmente desperdícios. Entretanto, a redução de custos 
unitários não implica necessariamente redução global de despesas. Quem determina o montante da despesa são os condicionantes macroeconômicos e políticos, tais como evolução das receitas tributárias e do estoque da dívida pública, situação do balanço de pagamentos, padrão de resposta às demandas sociais, legislação em vigor etc. A adoção dos sistemas de custos deverá alterar não propriamente o montante da despesa, mas sua composição, assim como a quantidade e a qualidade dos serviços prestados, em decorrência da melhoria de desempenho. Ou seja, a gestão de custos produzirá efeitos alocativos na despesa governamental.

\section{Como apurar custos no serviço público?}

As medidas de desempenho, entre elas os custos, só fazem sentido se vinculadas a sistemas de avaliação de desempenho institucional. As concepções modernas de avaliação institucional pressupõem um mínimo de planejamento estratégico e de gestão de processos de trabalho nas organizações. Não se trata, portanto, de medir por medir, mas sim de medir o que é relevante para a avaliação do desempenho corrente e para a identificação de tendências (ou descontinuidades), com relação ao desempenho futuro.

O bom desempenho das organizações governamentais depende da utilização racional dos recursos disponíveis na busca das metas priorizadas no planejamento estratégico. Também depende de ações que realinhem as tendências da organização com seus objetivos estratégicos. Nesse contexto é que se devem buscar medidas de desempenho. Se a ênfase da avaliação recai meramente na medição (ou nos métodos de custeio), corre-se o risco da organização atingir padrões eficientes na prestação de serviços que têm pouca importância para os usuários ou cidadãos, comprometendose a eficácia e a efetividade das atividades que deveriam ser prioritárias para a administração pública.

O planejamento estratégico define os objetivos que a organização quer atingir no futuro (horizonte de planejamento), assim como os macroprocessos (as grandes funções da organização). Tais definições devem ser consistentes com a missão e a visão de futuro da organização. O detalhamento operacional dos objetivos estratégicos produz a definição das metas para um determinado período, ao passo que o desdobramento dos macroprocessos resulta na definição/redesenho dos processos de trabalho. Na definição dos novos processos de trabalho, ou no mapeamento dos já existentes, procede-se a uma descrição razoavelmente detalhada das atividades que os compõem. Esse mapa de processos e a lista de atividades são a matéria-prima para os modernos sistemas de custos. Como será visto mais adiante, o método $\mathrm{ABC}$ parte da hipótese 
fundamental segundo a qual são as atividades, e não os produtos, que consomem recursos na organização. São as atividades que geram custos. Assim, um sistema de custo ABC essencialmente mostra quais são as atividades e como elas geram os custos.

A potencialidade do uso da metodologia $\mathrm{ABC}$ nos processos de mudança organizacional e nos programas de qualidade tem sido destacada na literatura especializada: "o melhor local para controlar custos é no nível dos processos. Quando se depende de um sistema de contabilidade orçamentária e de verbas, muitas decisões financeiras são tomadas arbitrariamente. Ao invés de reduções de custos seletivas e focalizadas, é-se forçado a adotar reduções (lineares horizontais) e outras abordagens radicais. Na maioria dos casos, isso acontece simplesmente porque os gerentes de nível superior não têm idéia de quais partes do processo agregam mais valor aos produtos e serviços e quais as que agregam menos. Os funcionários no nível dos processos são capazes de determinar esse valor, mas precisam ter um indicador do custo real. $\mathrm{O}$ custo baseado em atividade fornece esse tipo de informação". ${ }^{16}$

\section{Fundamentos do ABC}

A hipótese fundamental (e revolucionária) do ABC é de que os custos são gerados pelas atividades. Como conseqüência, pelo mapeamento das atividades, pode-se fazer uma descrição mais acurada da forma pela qual os recursos são consumidos dentro de uma organização. O mapeamento identificará quais atividades agregam valor ao produto e quais não agregam. Para cada atividade é avaliada a taxa de consumo de recursos. Pode-se, inclusive, comparar o custo da atividade com o valor que ela adiciona ao produto (análise custo-valor de Yoshikawa). ${ }^{17}$ Enfim, o ABC mostra como se formam os custos nas organizações, enquanto que o custeio tradicional se limita a apurar quais são os custos. Este método também serve para simular o impacto sobre a estrutura ele da organização decorrente da eliminação, modificação ou criação de uma atividade.

\subsection{ABC: esquema conceitual}

O processo de trabalho é conceituado como uma cadeia de atividades que transformam insumos em produtos, de modo a adicionar valor ao cliente. Ou seja, as atividades são o link entre os insumos e os produtos. Para quantificar a relação entre uma atividade e um insumo, usa-se um gerador de custos (cost driver) de recursos. As taxas de 
consumo de recursos, associadas a cada cost driver, podem ser tecnicamente determinadas (medições) ou estimadas com base em padrões referenciais (de benchmarking) ou em hipóteses. Para quantificar a relação entre uma atividade e um produto, ou outro objeto de custeio (cliente, unidade, projeto, canal de distribuição etc.), usa-se um gerador de custos (cost driver) de atividade. ${ }^{18}$

As atividades não relacionadas diretamente com produtivos poderão compor processos de suporte a clientes, processos de desenvolvimento de projetos etc. Quase todas as despesas são apropriadas como custos a alguma atividade definida na lista de atividades da organização. Assim, o quantum de despesas (indiretas ou fixas) não identificadas com alguma atividade fica reduzido a um mínimo, quando comparado aos métodos de custeio tradicionais. Tais resíduos serão objeto de rateio pelos critérios tradicionais ou contabilizados como despesas (que não são custos).

Como exemplo, podemos idealizar um processo de trabalho típico da área meio de qualquer organização governamental. Vamos denominálo gestão da despesa com pessoal. Algumas das principais atividades desse processo são:

- cadastramento de novos servidores (A1);

— atualização do cadastro (A2);

— manutenção do cadastro de pessoal (A3);

— análise de petições (de diárias, de férias, benefícios etc.) dos servidores (A4);

— atendimento no balcão, telefone, intranet (A5);

— preparação da folha de pagamento (A6);

— preparação de relatórios sobre a despesa com pessoal (A7).

Alguns dos insumos utilizados nesse processo são: pessoal, material de consumo e serviços de informática, todos rubricas de despesa do Siafi.

Assim, um cost driver de recurso que vincula o recurso despesa com pessoal à atividade cadastramento de novos servidores poderia ser $\mathrm{o}$ número de servidores novos cadastrados. Um cost driver que vincula o recurso despesa com serviços de informática à atividade processamento da folha de pagamento poderia ser o número de servidores.

Já o produto folha de pagamento terá custos gerados a partir de várias das atividades acima (A1, A2, A3, A6 e A7), apropriados por cost drivers de atividade como tempo de processamento, número de atualizações do cadastro etc.

Com a finalidade de gerar relatórios sobre custos, podem ser associados atributos às atividades. Os atributos são esquemas de codificação associados a cada atividade, que facilitam a geração de relatórios de custos para análises específicas. Exemplos de atributos: nível hierárquico da atividade, natureza da atividade, volatilidade do custo da atividade etc. 
5.2. Por que adotar uma metodologia de custos tão sofisticada quanto o $\mathrm{ABC}$ se o setor público não tem sequer uma cultura de custos?

Além das vantagens já destacadas em relação aos sistemas tradicionais, o ABC é particularmente adequado ao setor público porque:

1) foi concebido para apurar custos não somente de produtos (bens ou serviços), como também de outros objetos de custeio: processos, clientes, projetos, metas, programas de governo, unidades governamentais, entre outros. Esse ponto é mais relevante do que pode parecer à primeira vista. O custeio tradicional restringe os objetos de custeio aos produtos. Porém, em muitas áreas do serviço público, fica até um pouco difícil identificar, de forma precisa, qual é o produto. Essa dificuldade vem sendo constatada nos levantamentos de processos feitos nos últimos anos em órgãos do governo federal. Os produtos do setor público típico são, regra geral, serviços não-homogêneos, de natureza complexa e sem similar no mercado;

2) o custo total de um produto é obtido pela agregação do custo indireto ao direto. $\mathrm{E}$ o custo indireto depende de critérios de rateio um tanto arbitrários. Além do mais, devido ao progresso tecnológico, os custos fixos e indiretos vêm tendo um peso crescente na composição do custo total de muitos produtos, tornando ainda mais problemática a definição arbitrária de critérios de rateio;

3) os sistemas ABC têm uma arquitetura flexível, particularmente adequada a organizações complexas, com processos em constante mutação, compatíveis com altos padrões tecnológicos;

4) o ABC é uma ferramenta poderosa em programas de reestruturação e de melhoria de gestão, pois não apenas apura os custos já incorridos, como também é particularmente útil para simular os impactos sobre custos decorrentes de ações de melhoria de processos ou de reengenharia dos mesmos. Em particular, o ABC instrumentaliza cortes seletivos de despesa em programas de ajuste fiscal, minimizando o impacto negativo desses programas.

\subsection{A implantação de sistemas de custos depende da convergência dos sistemas de informações já existentes no governo?}

Categoricamente, não! O ABC vai se alimentar das informações sobre a despesa (informada pelo Siafi), das listas de atividades das organizações com os respectivos cost drivers e objetos de custeio, sendo seu processamento totalmente paralelo (roda em rede local) ao do Siafi e Siape, não interferindo de forma alguma na execução orçamentária e financeira. 
De fato, a convergência de sistemas é crucial para o funcionamento de sistemas corporativos como o SIPE (Sistema Integrado de Pessoal) e o SIADS (Sistema Integrado de Administração de Serviços), ou mesmo o Siape e o Siafi. Outros sistemas de informações do governo também dependerão da referida convergência. Também foi importante para o PAGG (Programa de Acompanhamento dos Gastos do Governo), ${ }^{19}$ pois somente após a unificação da tabela de órgãos dos dois sistemas (Siafi e Siape), é que foi possível gerar os relatórios de gastos por Unidade de Controle de Gasto (UCG). Tal não é o caso dos sistemas de custos ABC.

\subsection{Por que implantar sistemas de custeio} ABC, se o governo já dispõe do PAGG?

Porque os sistemas de custos $\mathrm{ABC}$ informam custos, enquanto que o Siafi e o PAGG informam despesa. Assim, os sistemas de custos ABC irão complementar as informações já disponibilizadas pelo Siafi, inclusive os relatórios de gasto por UCG, gerados pelo PAGG.

A novidade, no PAGG, é a geração de relatórios que informam a execução da despesa com base nos níveis hierárquicos mais elevados da estrutura de cada órgão. É certo que o PAGG acrescenta informações úteis em relação às informações anteriormente disponibilizadas pelo Siafi, pois associa a despesa executada com os gestores de nível hierárquico mais elevado (DAS-6), avançando na direção da accountability. Porém, o PAGG sofre da mesma limitação do Siafi: ele desconhece os produtos e os processos de trabalho das organizações governamentais. Assim como os demais relatórios do SIAFI, o PAGG informa despesa (por UCG), mas não informa custos. Daí por que a proposição de um sistema de custos na metodologia $\mathrm{ABC}$ não é contraditória ou se superpõe ao PAGG. Ao contrário, as informações sobre custos complementam as informações já disponíveis sobre as despesas do governo e dão maior consistência a essas. É o que já se mostrou possível (e necessário) no setor privado, não havendo por que não ocorrer no setor público.

\subsection{Outras características do ABC}

\subsubsection{Padronização dos sistemas ABC}

Ao contrário dos sistemas de informação sobre a despesa do governo, os sistemas de custos não apresentam uma estrutura de dados padronizada (como o plano de contas da União), pois os custos de cada organização governamental dependem da natureza dos serviços prestados e da forma pela qual são executados (conforme o mapa dos processos de trabalho). Ou seja, os sistemas de custos devem ser desenhados sob medida para as necessidades de cada organização governamental. Com o passar 
do tempo, a expansão de sistemas ABC pela administração pública tornará possível (e desejável) o aproveitamento das listas de atividades de algumas organizações governamentais por outras (benchmarking). Até porque muitas atividades são executadas de forma similar em diversas organizações. Esse é o caso, por exemplo, de atividades e processos de trabalho da área meio. Nesses casos, as organizações que estiverem implantando ou aprimorando sistemas $\mathrm{ABC}$ poderão se beneficiar dos dicionários de atividades, cost drivers e atributos já definidos no serviço público, copiando-os ou adaptando-os.

\subsubsection{Prazos e custos}

Um projeto de implantação de um sistema de custos $A B C$ pode apresentar resultados apreciáveis em curto prazo (seis meses), uma vez iniciado o desenvolvimento do mesmo. O custo de desenvolvimento e de implantação de tal sistema não deverá ser elevado se comparado a outros projetos de modernização ou reestruturação governamental.

\subsubsection{Condicionalidades}

É importante ressaltar que a implantação de sistemas de custos não depende da ação conjunta de órgãos de governo, nem de alteração na legislação em vigor. Depende apenas de determinações internas da organização governamental que se propuser a empreender tal projeto.

\subsubsection{Impacto na execução orçamentária}

Outra característica importante dos sistemas de custos ABC é a seguinte: a apuração dos custos não irá interferir na execução orçamentária e financeira. De fato, os custos poderão ser apurados periodicamente (mensalmente, por exemplo), sem ser necessário condicionar a execução orçamentária ou financeira. Nesse sentido, a apuração dos custos será paralela à execução orçamentária/financeira, não necessitando ser on line. Também não haverá necessidade de se alterar a estrutura de dados do Siafi e do Siape. O sistema de custos vai processar informações geradas pelo Siafi/Siape, com base no mapa de processos de trabalho da organização governamental.

\subsubsection{Grau de detalhamento do ABC}

O desenvolvimento de sistemas de custos deverá passar pelo crivo da análise de custo-benefício, pois o gasto implantação/manutenção de sistemas de custos depende diretamente do grau de complexidade desses sistemas. Assim, o grau de complexidade dos sistemas de custos deve ser confrontado com o benefício das informações gerenciais por eles 
geradas. Como bem observaram Kaplan\&Cooper: "o número de atividades é função do propósito do modelo e da dimensão e complexidade organizacional que está sendo estudada".

\subsubsection{Custos e capacitação gerencial}

Ao longo deste trabalho procuramos mostrar que o custo é uma ferramenta poderosa para melhorar o desempenho das organizações governamentais. Se é assim, então devem ser desenvolvidas as competências para implantar sistemas de custos e gerenciar corretamente as informações por eles geradas. Há de se fazer um grande esforço de capacitação da administração pública para a gestão (estratégica) de custos, pois a revolução dos custos só será vitoriosa se os gestores abraçarem a causa. Nesta direção, não poderíamos deixar de registrar a iniciativa pioneira da Escola Nacional de Administração Pública (ENAP), que a partir de meados de 1998 passou a ministrar o curso "Gerenciamento de custos no serviço público".

\begin{tabular}{|l|l|}
\hline Gestão de custos ABC/ABM & $\begin{array}{l}\text { Controle de despesas e custeio tradi- } \\
\text { cional }\end{array}$ \\
\hline $\begin{array}{l}\text { Os custos são determinados pelas ativi- } \\
\text { dades e pelos cost drivers }\end{array}$ & $\begin{array}{l}\text { Os custos são determinados pelos centros } \\
\text { de custos e pelos critérios de rateio }\end{array}$ \\
\hline $\begin{array}{l}\text { Poderá ser uma inovação introduzida pela } \\
\text { reforma administrativa }\end{array}$ & $\begin{array}{l}\text { Típico do modelo tradicional de adminis- } \\
\text { tração pública }\end{array}$ \\
\hline $\begin{array}{l}\text { Finalidade principal: } \\
\text { Melhorar o desempenho das organiza- } \\
\text { ços governamentais }\end{array}$ & $\begin{array}{l}\text { Finalidade principal: } \\
\text { Controle da despesa, assegurando a legali- } \\
\text { dade dos atos de gestão }\end{array}$ \\
\hline $\begin{array}{l}\text { Mostra as causas do mau desempenho e } \\
\text { como melhorá-lo }\end{array}$ & $\begin{array}{l}\text { Mostra que há mau desempenho, mas não } \\
\text { identifica as causas }\end{array}$ \\
\hline $\begin{array}{l}\text { Parametriza a função alocativa do governo, } \\
\text { gerando indicadores de eficiência e eficácia } \\
\text { Ênfase nos resultados e nos custos uni- } \\
\text { tários }\end{array}$ & $\begin{array}{l}\text { Parabeniza a política fiscal } \\
\text { Enfase nos insumos (pessoal, compras, } \\
\text { contratos etc) e nos agregados fiscais. }\end{array}$ \\
\hline $\begin{array}{l}\text { Influencia o comportamento dos gestores } \\
\text { das organizações governamentais }\end{array}$ & $\begin{array}{l}\text { Influencia basicamente os sistemas admi- } \\
\text { nistrativos (financeiro, orçamentário e de } \\
\text { controle interno) }\end{array}$ \\
\hline Accountability & Impessoalidade \\
\hline $\begin{array}{l}\text { Responsabiliza pessoalmente os gesto- } \\
\text { res/dirigentes }\end{array}$ & $\begin{array}{l}\text { Responsabiliza os sistemas (financeiro, } \\
\text { orçamentário e de controle interno). }\end{array}$ \\
\hline $\begin{array}{l}\text { Não-obrigatoriedade legal: } \\
\text { Não tem obrigatoriedade legal, mas é de } \\
\text { alto interesse para a administração }\end{array}$ & $\begin{array}{l}\text { Obrigatoriedade legal: } \\
\text { É de uso obrigatório, conforme o dispos- } \\
\text { to na Constituição Federal, na lei federal } \\
n^{\circ} 4.320 / 64 \text { e demais disposições legais. }\end{array}$ \\
\hline
\end{tabular}


Já está bem amadurecida a necessidade de o setor público no Brasil implantar sistemas de custos. Tais sistemas não precisarão reproduzir toda a evolução dos sistemas de custos do setor privado. É possível e é desejável que os sistemas de custos governamentais sejam desenhados na metodologia $\mathrm{ABC}$, queimando etapas que o setor privado já trilhou e maximizando os benefícios que as informações geradas por tais sistemas propiciarão. A experiência americana recente não deixa dúvidas sobre a viabilidade dessa tese. 


\section{Alguns conceitos utilizados neste trabalho}

\section{Accountability}

"Sob a óptica da Teoria dos Contratos, sempre que alguém (principal) delega parte de seu poder ou direitos a outrem (agente), este assume a responsabilidade de, em nome daquele, agir de maneira escorreita com relação ao objeto da delegação e, periodicamente, até o final do mandato, prestar contas de seus desempenhos e resultados. A esta dupla responsabilidade, ou seja, agir de maneira escorreita e prestar contas de desempenhos e resultados, dá-se o nome de accountability." (Nakagawa[94], p.19)

\section{Acurácia}

É uma qualidade da informação quantitativa, no caso custos, que dá maior eficácia ao processo decisório. Distingue-se, portanto, da exatidão, que é uma qualidade que propicia maior eficiência no processo decisório.

\section{Gastos do governo}

São sacrifícios financeiros que o governo faz com vistas ao financiamento de suas atividades ou de suas decisões.

Eliseu Martins define como terminologia para custos industriais: "Gasto é o sacrifício financeiro com que a entidade arca, para a obtenção de um produto ou serviço qualquer, sacrifício esse representado por entrega ou promessa de entrega de ativos (normalmente dinheiro)".

\section{Despesa do governo}

É o gasto do governo, que tem como contrapartida redução no saldo da conta caixa.

Pela lei $\mathrm{n}^{\circ} 4.320 / 64$, as despesas são contabilizadas pelo regime de competência do exercício, ou seja, pela data do fato gerador e não pelo seu efetivo desembolso financeiro. A despesa é, portanto, contabilizada quando incorrida (autorizada) e não quando é paga.

No setor público, todos os gastos são contabilizados como despesas (orçamentárias ou extra-orçamentárias). O mesmo não ocorre no 
setor privado, daí termos feito a distinção entre gastos e despesas do governo. Na contabilidade de custos tradicional, só são contabilizados como custos os gastos direta ou indiretamente relacionados com a produção. Os demais gastos são contabilizados como despesas. Exemplo: despesas financeiras, despesas com vendas, despesas administrativas etc. Assim, o esquema contábil tradicional começa pela separação entre despesas e custos, depois separa os custos diretos dos indiretos e finalmente procede-se ao rateio dos custos indiretos.

Eliseu Martins define como terminologia para custos industriais (privados): "Despesa é o gasto com bem ou serviço consumido direta ou indiretamente na obtenção de receitas."

\section{Custo de produto}

São gastos incorridos na elaboração de um bem ou na prestação de um serviço.

O gasto só é contabilizado como custo quando é consumido no processo de produção do bem ou serviço.

Eliseu Martins define como terminologia para custos industriais: "Custo é o gasto relativo a bem ou serviço utilizado na produção de outros bens ou serviços."

\section{Processo de trabalho}

É uma cadeia de atividades que transforma recursos (ou insumos) em produtos. Tais atividades devem ser aquelas que agreguem valor ao cliente ao qual é destinado o produto.

Considera-se bem caracterizado um processo de trabalho numa organização quando estão identificados os fornecedores dos insumos, os insumos, a cadeia de atividades (com o respectivo padrão tecnológico), os produtos e os respectivos clientes. Adicionalmente, na análise de processos, normalmente: a) atribui-se um nome ao processo; b) identifica-se o responsável pela gestão do processo e c) identificam-se os indicadores de desempenho.

\section{Custo de processo de trabalho}

São gastos incorridos na execução das atividades que compõem o processo de trabalho.

Este é um conceito relevante na metodologia $\mathrm{ABC}$ : quem consome os recursos das organizações são as atividades.

\section{Custo direto}

É a parcela do custo total que é univocamente identificada com o produto (ou com o processo de trabalho). 
É a parcela do custo total que não pode ser identificada diretamente com um produto (ou processo) específico, ainda que seja essencial para a produção do mesmo. Depende, portanto, de critérios de rateio (entre os produtos, processos ou outros objetos de custeio).

\section{Departamentos}

São as unidades mínimas na estrutura organizacional que serão objeto de controle para a contabilidade de custos. Cada departamento terá um responsável pelos seus custos (centro de responsabilidade).

Assim, nem toda unidade da estrutura é um departamento sob a óptica do controle de custos.

\section{Centro de custos}

É o locus onde são acumulados os custos indiretos para posterior alocação (rateio) aos produtos ou a outros departamentos.

Normalmente, a cada departamento corresponde um centro de custos. Pode haver casos, entretanto, de mais de um centro de custos num departamento. ${ }^{20}$

\section{Custo fixo}

É a parcela do custo total que não varia com o nível de produção.

\section{Custo variável}

É a parcela do custo total que varia com o nível de produção. Quanto maior o volume de serviço prestado, maior o custo variável.

\section{Custo médio}

É obtido pela divisão do custo total pelo volume de produção realizado (ou de serviço prestado).

A unidade de medida do custo médio depende da unidade de medida do produto (ou serviço).

\section{Custo marginal}

É a variação no custo total decorrente de um aumento no nível de produção.

Só não há distinção entre o custo médio e o custo marginal quando o custo total é proporcional ao nível de produção. Nos demais casos, mesmo quando a função custo total é linear (com custo fixo diferente de zero), há distinção entre o custo médio e o marginal. 


\section{Programa de Acompanhamento dos Gastos do Governo - PAGG}

O PAGG, instituído por decreto em junho de 1997, compreende um conjunto de ações que visam gerar relatórios de controle da despesa executada pelas principais unidades administrativas ${ }^{21}$ da estrutura dos órgãos da Administração Direta, denominadas Unidades de Controle de Gasto (UCGs). O decreto formalizou uma demanda do ministro Bresser Pereira, ${ }^{22}$ feita no $2^{\circ}$ semestre de 1996 , que queria saber o valor das despesas executadas pelas principais unidades administrativas de cada ministério.

Inicialmente, são identificadas para o Siafi as unidades escolhidas pelo ministério para serem objeto de controle de gasto pelo PAGG, ou seja, são definidas as UCGs. Para cada UCG é criada uma Unidade Gestora Responsável (UGR), que é o endereço no SIAFI onde são totalizadas as despesas associadas diretamente à Unidade de Controle de Gasto, que estamos denominando de despesas diretas. Além das despesas diretas, o PAGG prevê, na sua concepção original, a apropriação das despesas indiretas, ou seja, despesas gerais do ministério que não podem ser diretamente identificadas em cada UCG. Despesas como: serviço de energia elétrica, água, vigilância, limpeza, suporte da rede de informática etc. seriam rateadas entre as UCGs a partir de critérios de rateio padronizados, tais como número de servidores de cada UCG, área ocupada pela UCG etc. Tais critérios estão contidos no algoritmo de rateio que será executado pelo módulo gerencial do Siafi. Assim, a despesa total da unidade seria apurada de acordo com o esquema a seguir:

Despesa total $=$ Despesa direta + Despesa indireta da unidade (UCG) (Rateio no módulo Siafi)

As despesas diretas são lançadas nas respectivas UGRs (Unidades Gestoras Responsáveis) do Siafi. Para tanto, foi necessário refazer a tabela de UGR's do Siafi, de modo que a cada UCG correspondesse uma UGR. Esta forma de apurar a despesa direta das UCGs por meio das UGRs do Siafi é bastante conveniente, pois aproveita a estrutura de dados do Siafi e não interfere na execução orçamentária e financeira, dado que as notas de empenho e as ordens bancárias são geradas pelas UGEs (Unidades Gestoras Executoras). As despesas diretas referentes à força 
de trabalho ${ }^{23}$ vêm sendo obtidas, de forma análoga, a partir do Siape. ${ }^{24}$ Para tanto, foi necessário refazer a tabela das UORGs ${ }^{25}$ e atualizar a força de trabalho lotada em cada unidade administrativa. Em suma, as UGRs e as UORGs fazem o papel de centros de custos, e as UCGs, o papel dos departamentos, na linguagem da contabilidade de custos. As despesas indiretas da UCG deverão ser apuradas a partir do rateio das despesas gerais centralizadas nas UGEs. Os relatórios do PAGG conterão ainda agregações ou detalhamentos das despesas por UCG que forem consideradas relevantes pelos dirigentes de cada ministério. $\mathrm{O}$ mais importante no relatório é a responsabilização do dirigente da unidade administrativa com a despesa da mesma.

\section{Notas}

1 O autor expressa seu agradecimento à Dra. Vera Petrucci, Diretora de Pesquisa e Difusão da ENAP, pela boa acolhida dada ao texto ainda em sua versão preliminar; ao Dr. José Nivaldo Gomes Cordeiro, Subsecretário de Gestão Interna, pelo apoio institucional dado ao trabalho no âmbito do Ministério da Administração; aos Professores Masayuki Nakagawa e Wellington Rocha (USP), Leão Carvalho (FGV) e Jameson Reinaux (UnB), pelas idéias luminosas; ao Celso e André Sanseverino, da ABC Costing, pela cooperação valiosa; ao Maurício Muniz, coordenador do curso de custos da ENAP, pelas dicas preciosas; aos Comandantes Alceu e Hiram, do Ministério da Marinha, pela troca de experiências.

2 Tanzi, Vito in "Qualidade do gasto público", palestra proferida no Seminário Internacional de Finanças Públicas. Setembro de 1996. Brasília: ESAF/MF.

3 Ver as publicações dos autores Kaplan \& Cooper, Kehoe, Littman \& Carr, Kaplan \& Norton, citadas nas referências bibliográficas, e as seguintes páginas da Internet: "Performance Economic Review e ABC Technologies".

4 Ver Osborne\&Gaebler, citado na bibliografia, especialmente o capítulo "Governo Competitivo".

5 A teoria dos bens públicos, devida principalmente a P.A.Samuelson, classifica os bens econômicos em: a) bens públicos (ou bens públicos puros); b) bens semi-públicos; c) bens privados.

O bem privado tem as características de consumo rival e excludente. Ou seja, o consumo de maior quantidade de um bem privado por um consumidor, dada a oferta, implica menor consumo para os demais consumidores (consumo rival). Por outro lado, só tem acesso ao consumo do bem privado os consumidores que pagarem por ele. Os demais consumidores são excluídos do consumo (Princípio da Exclusão). O bem público (puro), ao contrário, não apresenta rivalidade no consumo e nem exclusão para quem não paga (espontaneamente) por ele. É o caso da defesa nacional, da segurança pública, do corpo de bombeiros, da saúde pública, da justiça pública, da qualidade ambiental etc. Para esses bens o usuário atribui utilidade, mas "não revela sua preferência", pois, decidindo 
não pagar, o usuário não pode ser excluído do consumo do serviço. Não é possível, portanto, a estimativa da curva de demanda. $O$ financiamento do custo de produção não pode ser feito pelo mercado. Será feito, então, via tributos. Os bens semipúblicos, como os serviços de educação e saúde, apresentam consumo rival e excludente, mas apresentam também externalidades. Ou seja, o benefício social é maior que o benefício privado (internalizado pelo consumidor), o que também justifica a intervenção governamental. Ver Mussgrave ou Pindyck\&Rubinfeld, citados nas referências bibliográficas.

6 Neste caso, a teoria econômica fala em curva de "pseudo-demanda", indicando que os consumidores atribuem algum nível de utilidade ao consumo do bem público, mas "não revelam sua preferência".

7 Se é verdade que não há cultura de custos no setor público, também devem ser registradas algumas iniciativas importantes nesta área no âmbito federal. O ministério da Aeronáutica dispõe de um sistema de custos desde os anos 70. Porém, tal sistema apresenta-se defasado e já vem sendo objeto de reformulação pelo próprio ministério. O Ministério da Marinha também dispõe de um sistema de custo-padrão para as atividades de manutenção e reparo de embarcações. O Hospital Marcílio Dias, vinculado ao mesmo ministério, também dispõe de um sistema de custos (custo-padrão). Entretanto, as experiências mais interessantes que tivemos oportunidade de conhecer no setor público federal foram a da Empresa Brasileira de Correios e Telégrafos e a da Telemig. Essas duas empresas estatais já possuíam sistemas tradicionais de custeio, considerados insatisfatórios. Essas empresas empreenderam esforços no sentido de desenvolver sistemas de custo na metodologia ABC, a partir do segundo semestre de 1997. Pelas informações a que tivemos acesso, a implantação do $\mathrm{ABC}$ vem sendo muito bemsucedida. Ambas as empresas desenvolveram seus sistemas com suporte do software Oros ABC, da ABC Technologies. A Embrapa, empresa federal de pesquisa agropecuária, vem desenvolvendo nos últimos tempos um sofisticado sistema de avaliação institucional, na metodologia Balanced Scorecard (BSC). O BSC da Embrapa está sendo complementado este ano por um sistema de custos ABC.

8 Referimo-nos, no caso brasileiro, à lei das Sociedades por Ações, lei n ${ }^{\circ} 6.404 / 76$, que, entre outras disposições, estabeleceu a obrigação legal de determinadas demonstrações contábeis.

9 Ver conceito de acurácia no Anexo I.

10 Ver "Contabilidade de Custos", de Eliseu Martins, citado nas referências bibliográficas.

${ }^{11}$ Entre as instituições governamentais nos EUA e Canadá que implantaram sistemas de custos ABC, podemos citar a Receita Federal , a Força Aérea, a Marinha, o Exército, o Ministério da Agricultura, a Agência de Serviços Gerais (GSA), entre outros.

12 Para uma análise das diferenças entre o $\mathrm{ABC}$ e os métodos de custeio tradicionais, ver nas referências bibliográficas Kaplan \& Cooper, citado.

13 Vide Deming, W.E. (1982). Qualidade: a revolução da administração, cap.1.

14 Mantidos o nível de satisfação dos usuários e a qualidade intrínseca do serviço.

15 Com a promulgação da emenda constitucional no 19, em junho de 1998.

16 Citação do livro "Excelência nos Serviços Públicos", de David Carr e Ian Littman, Ed. Qualitymark, 1991, p.74; ver também: A Estratégia em Ação de Robert Kaplan e David Norton, Harvard Business School Press, 1.997; ABC - Custo baseado em atividade de Massayuki Nakagawa, ed. Atlas, 1993.

17 Ver Nakagawa, citado nas referências bibliográficas.

18 Ver Kaplan\&Cooper ou Nakagawa, citados nas referências bibliográficas.

19 Sobre o PAGG, ver anexo II.

20 Ver Eliseu Martins, Cap. 6, seção 6.3. 
${ }^{21}$ Em sua concepção original, o PAGG previa a apuração das despesas das secretarias e dos departamentos. Porém, até o final de 1998, estavam sendo apuradas apenas as despesas das secretarias.

22 Por determinação do ministro Bresser, formulamos a primeira versão do PAGG, na época denominado Projeto Contabilidade Pública Gerencial. O modelo conceitual do PAGG já estava delineado no documento de nossa autoria, de novembro de 1996, intitulado "Contabilidade Pública Gerencial: em busca da Qualidade do Gasto Público", aprovado pelo Ministro do MARE, Bresser Pereira, pelo Secretário Federal de Controle, Domingos Poubel, e pelo então Secretário do Tesouro Nacional, Murilo Portugal. Tivemos a colaboração de vários dirigentes de áreas técnicas do Ministério da Administração, do Ministério da Fazenda e do Ministério do Planejamento e Orçamento. Já naquela época alertávamos para o fato de que o PAGG era um sistema de apuração da despesa por unidade administrativa, e que seria fundamental para o serviço público a implantação de sistemas de custos propriamente ditos. Posteriormente, já em 1997, foi instituído um grupo de trabalho interministerial que teve a responsabilidade de coordenar o PAGG. A Coordenação Executiva coube, a partir daí, ao Dr. João Elias, da Secretaria Federal de Controle, do Ministério da Fazenda.

23 A força de trabalho é o conjunto de pessoas que efetivamente participam dos processos de trabalho da organização, independente de seu vínculo. Esse conjunto pode ser apurado a partir dos servidores do quadro de pessoal da organização governamental, mais os servidores requisitados e ocupantes de cargos DAS sem vínculo, menos os servidores cedidos ou licenciados, mais o pessoal contratado (terceirizados ou estagiários). O relevante, em termos gerenciais, é o custo da força de trabalho, e não o valor da folha de pagamento, de acordo com a fonte pagadora.

Ministérios como o da Administração (MARE) cedem muitos servidores a outros ministérios; porém, a despesa do pessoal cedido é incluída na folha de pagamento do MARE. Numa análise de desempenho, a despesa com o pessoal cedido deve ser descontada do custo da força de trabalho, pois o pessoal cedido efetivamente não presta serviços para a organização. Por outro lado, em muitos órgãos, a força de trabalho é substancialmente composta por servidores requisitados (é o caso da Presidência da República). O custo dos requisitados deve, nesses casos, compor a força de trabalho da unidade.

Por conta desse conceito, o PAGG passou a denominar de gastos as despesas apropriadas pelas Unidades de Controle de Gastos, independentemente da Unidade Pagadora (UPAG).

24 O Siape é o Sistema Integrado de Administração de Pessoal. Trata-se de um banco de dados informatizado que tem como principal finalidade gerar a folha de pagamentos do pessoal civil do Poder Executivo Federal.

${ }^{25}$ UORG, unidade organizacional, e UPAG, unidade pagadora, são conceitos que definem a forma pela qual a estrutura do Siape processa a despesa com pessoal. Tais conceitos são similares aos conceitos de UG, Unidade Gestora, do Siafi.

\section{Referências bibliográficas}

ABC Technologies. Homepage na Internet.

Alonso, Marcos. (1997), “Agências Executivas: estratégias de reforma para a administração indireta”. Série Texto para Discussão n. 18. Brasilia: ENAP. 
Alonso, Marcos. (1996), Contabilidade Pública Gerencial (mimeo.).

Alonso, Marcos. (1996), "Por um sistema de custos para o Serviço Público". Nota Técnica n. 05. Documento interno do Ministério da Administração (MARE).

CARR, D. \& I. Littman. (1992), Excelência nos serviços públicos. Rio de Janeiro: Qualitymark. Conselho Federal de Contabilidade - CFC . Custo comoferramenta gerencial. São Paulo: Atlas.

KaPlan, R. \& D. Norton. (1997), A estratégia em ação: Balanced Scorecard. Rio de Janeiro: Campus.

Kaplan, R. \& R. Cooper. (1998). Custo e Desempenho, São Paulo: Futura.

KeHOE, J. et allii. (1995), Activity-based management, Arlington, EUA: Coopers \& Librand.

MARE. Homepage na Internet.

Martins, Eliseu. Contabilidade de Custos. São Paulo: Atlas.

Musgrave, R. \& P. Musgrave. (1980), Finanças Públicas. Rio de janeiro: Campus.

Nakagawa, M. (1994), ABC: custeio baseado em atividade. São Paulo: Atlas.

Nakagawa, M. (1993), Gestão Estratégica de Custos. São Paulo: Atlas.

National Performance Review. Homepage na Internet.

Osborne, D. \& T. Gaebler. (1994), Reinventando o governo. Brasília: comunicação.

Pindyck, R. \& Rubinfeld. (1994), Microeconomia. São Paulo: Makron books.

Piscitelli, R. et all. Contabilidade Pública. Rio de Janeiro Atlas.

Player, S \& D. Keys. ABM: activity-based management. Rio de Janeiro: Arthur Andersen.

TeixeIra Machado. A lei 4.320 comentada. Rio de Janeiro: IBAM. 


\section{Custos no serviço público}

Marcos Alonso

A melhoria do desempenho da administração pública é uma necessidade que vem sendo evidenciada nesta década. Primeiro, porque o padrão da inserção do Brasil na economia mundial requer melhor desempenho do setor público, dado o caráter sistêmico da competitividade. Segundo, porque a crise fiscal do Estado exige que o governo faça mais com menos recursos. Daí a prioridade para a qualidade do gasto público. A proposta apresentada é que o governo desenvolva e implante sistemas de custos baseados em atividade (ABC), pois estes apresentam a flexibilidade necessária para o setor de serviços e são ferramentas úteis nos processos de reestruturação e de melhoria da gestão. Os sistemas ABC são superiores aos métodos de custeio tradicionais, pois: 1) reduzem as distorções do rateio dos custos indiretos e fixos; 2) não apenas apuram custos, mas também mostram como e onde se formam os custos, favorecendo uma mudança efetiva de atitude dos gestores.

\section{Costos en el servicio público}

Marcos Alonso

La mejoría del desempeño de la Administración Pública es una necesidad que viene evidenciándose en esta década. En primer lugar porque el patrón de la inserción de Brasil en la economía mundial requiere un buen desempeño del sector público, debido al caracter sistémico de la competitividad. En segundo lugar porque la crisis fiscal del Estado exige que el gobierno haga más con menos recursos. Por ese motivo se hace prioritario calificar los gastos públicos. Esta propuesta advierte que el gobierno desarrolle e implante sistemas de costos basados en actividades (ABC), pues estos presentan la flexibilidad necesaria para el sector de servicios y son herramientas útiles para los procesos de reestructuración y para la mejoría de la gestión. Los sistemas ABC son superiores a los métodos de costeo tradicionales, pues: 1) reducen las distorciones en la distribución de los costos indirectos y fijos; 2) no solamente descubren los costos, sino que también muestran cómo y dónde ellos se forman, incentivando un cambio de actitud efectivo de los gestores.

\section{Costs in public service}

\section{Marcos Alonso}

The need to improve the performance of Public Administration has become increasingly evident in this decade. Firstly, because the pattern of Brazil's inclusion in world economy requires better performance of the public sector, given the systemic character of competitiveness. Secondly, because the fiscal State crisis requires the government to do more with less resources. Thus, priority should be given to the quality of public expenditure. The proposal presented is for the government to develop and implement activity based on cost systems (ABC), as these possess the necessary flexibility for the service sector and are useful tools in restructuring and management improvement processes. The ABC systems are superior to the traditional costing methods since: 1) they reduce distortions of indirect and fixed cost allocation; 2) they not only find costs, but also show how and where costs are formed, which encourages effective change in the attitude of managers.
Revista do

Serviço

Público

Ano 50

Número 1

Jan-Mar 1999
Mestre em Economia pela USP. Especialista em Políticas Públicas e Gestão Governamental, atualmente na Assessoria da Secretaria de Estado da Administração e do Patrimônio/ SEAP / MOG 